\title{
Uncomplicated Acute Renal Failure and Post-Hospital Care: A Not So Uncomplicated Illness
}

\author{
Michael J. Fischer ${ }^{a, b} \quad$ Bradley B. Brimhall ${ }^{c}$ Chirag R. Parikh ${ }^{d}$ \\ a Department of Internal Medicine/Section of Nephrology, Jesse Brown VA Medical Center and University of Illinois \\ Medical Center, Chicago, III., ${ }^{b}$ Center for Management of Complex Chronic Care, Edward Hines, Jr. VA Hospital, \\ Hines, III., 'Tricore Reference Laboratories and Department of Pathology, University of New Mexico School of \\ Medicine, Albuquerque, N. Mex., and dDepartment of Internal Medicine/Section of Nephrology, Yale University \\ School of Medicine and Veterans Affairs Medical Center, New Haven, Conn., USA
}

\section{Key Words}

Acute renal failure, outcomes $\cdot$ Extended facility care $\cdot$

Home health care $\cdot$ Nephrology, clinical

\begin{abstract}
Background: Although uncomplicated acute renal failure (ARF) is associated with significant hospital resource utilization, its health care requirements following hospital discharge are not well understood. The goal of this study was to characterize the post-hospital care requirements incurred by patients with uncomplicated ARF and to determine its important influencing factors. Methods: We obtained hospital case mix data sets for a 2-year period (1999-2000) from the Massachusetts Division of Health Care Finance and Policy. Utilizing DRG and ICD-9-CM codes from 23 Massachusetts hospitals, we identified 2,128 adult patients whose primary reason for hospitalization was uncomplicated ARF. Post-hospital care was defined as the receipt of extended facility care or home health care following hospital discharge. Results: Nearly $50 \%$ of patients hospitalized with uncomplicated ARF required some type of post-hospital care, of whom $27 \%$ underwent extended facility care while $22 \%$ received home health care. The post-hospital care requirements for uncomplicated ARF were similar to those for serious medical conditions (e.g. heart failure) and exceeded
\end{abstract}

those of many common illnesses (e.g., bronchitis). Advancing age, worsening severity of illness, female gender, and emergency room admission were independently associated with receipt of post-hospital care $(p<0.05)$. A trend existed between less frequent post-hospital care requirements and hospitalization at academic medical centers compared with non-academic hospitals. Conclusions: Uncomplicated ARF is frequently associated with prolonged care following hospitalization. As the health care utilization for ARF becomes better characterized, these post-hospital care resources should not be overlooked.

Copyright $\odot 2008$ S. Karger AG, Basel

\section{Introduction}

Acute renal failure (ARF), especially when associated with non-renal organ failures or complicated ARF, has long been known to be associated with significant morbidity and mortality [1-10]. Recently, the effect of ARF on hospital costs and lengths of stay was investigated $[11,12]$. It appears that small acute rises in serum creatinine $(\geq 0.5$ $\mathrm{mg} / \mathrm{dl}$ ) can lead to substantial increases in hospital length of stay ( $>3$ days) and hospital costs ( $>7,000$ USD) [12]. Moreover, even ARF occurring in the absence of other organ failures, or uncomplicated ARF, is associated with

\section{KARGER}

(C) 2008 S. Karger AG, Basel

Fax +4161306 1234 E-Mail karger@karger.ch www.karger.com www.karger.com/ajn
Michael J. Fischer, MD, MSPH

University of Illinois at Chicago

Department of Medicine/Section of Nephrology (MC 793)

820 South Wood Street, Chicago, IL 60612-7315 (USA)

Tel. +1 312996 8477, Fax +1 312996 7378, E-Mail fischerm@uic.edu 
Table 1. Post-hospital care requirements (\%) for patients with uncomplicated ARF and other medical conditions following hospital discharge

\begin{tabular}{|c|c|c|c|c|}
\hline Hospital diagnosis (DRG and ICD-9-CM) & Prevalence $^{1}$ & $\begin{array}{l}\text { Post- } \\
\text { hospital care }\end{array}$ & $\begin{array}{l}\text { Extended } \\
\text { facility care }\end{array}$ & $\begin{array}{l}\text { Home } \\
\text { health care }\end{array}$ \\
\hline Cerebrovascular disorders except TIA (stroke) & $3.2(\mathrm{n}=16,527)$ & 65 & 52 & 13 \\
\hline Heart failure & $7.4(\mathrm{n}=37,883)$ & 52 & 25 & 27 \\
\hline ARF (uncomplicated) $)^{2}$ & $0.4(\mathrm{n}=2,128)$ & 49 & 27 & 22 \\
\hline Pneumonia and pleurisy & $8.1(\mathrm{n}=41,412)$ & 46 & 29 & 17 \\
\hline Circulatory disorders with AMI and complications & $2.7(\mathrm{n}=14,009)$ & 44 & 26 & 18 \\
\hline Cellulitis & $2.9(\mathrm{n}=14,790)$ & 37 & 17 & 20 \\
\hline Gastrointestinal hemorrhage & $3.6(\mathrm{n}=18,357)$ & 36 & 23 & 13 \\
\hline Bronchitis and asthma & $3.4(\mathrm{n}=17,182)$ & 14 & 6 & 8 \\
\hline
\end{tabular}

AMI = Acute myocardial infarction; TIA = transient ischemic attack.

${ }^{1}$ Numbers were calculated using the records of adult ( $>18$ years old) patients who survived to discharge and had been hospitalized for medical conditions (DRG and ICD-9-CM codes) in the dataset as the numerator and the total number of patient records in the dataset as the denominator $(\mathrm{n}=512,333)$.

${ }^{2}$ Additional records excluded if admission was from an extended care facility or the patient received mechanical ventilation or care in the intensive hospital care unit.

significant hospital resource utilization, exceeding that of many other common serious illnesses such as congestive heart failure and pneumonia [11].

In addition to being high resource utilizers within the acute hospital setting, patients with ARF may have significant health care needs following hospital discharge. A few recent studies have noted that up to $30 \%$ of surviving patients with ARF are discharged to extended care facilities $[13,14]$. In fact, one analysis found that ARF was independently associated with 2-fold higher odds for disposition to short- or long-term care facilities [13]. In order to more broadly explore the post-hospital care requirements engendered by ARF, we conducted a multicenter evaluation of a large cohort of adult hospitalized patients with uncomplicated ARF to assess not only their extended care facility stays but also their receipt of home health care services. By selecting patients whose primary reason for hospitalization was ARF, we sought to specifically characterize the relationship between this organ dysfunction and post-hospital care requirements.

\section{Subjects and Methods}

\section{Design, Data Source, and Study Population}

We conducted a retrospective analysis of a cohort of patients with uncomplicated ARF to examine their post-hospital care requirements and to determine the important influencing factors of such care. Unadjusted aggregate post-hospital care requirements for other common medical conditions requiring hospital- ization were described for comparison. We obtained the hospital case mix data sets of 23 Massachusetts hospitals for a 2-year period (1999-2000) from the Massachusetts Division of Health Care Finance and Policy (DHCFP) to perform all analyses.

In aggregate, 4,230 patient hospital discharge records were coded with a diagnosis-related group (DRG) code of 316 that corresponds to the broad diagnosis of renal failure (RF). The study population included only those records that specifically pertained to adult uncomplicated ARF as follows. First, 1,147 patient records were excluded because they did not have a principal diagnostic or International Classification of Diseases, 9th Revision, Clinical Modification (ICD-9-CM) code consistent with ARF [15]. The ICD-9-CM diagnostic codes consistent with ARF included 584.5 (ARF/tubular necrosis), 584.6 (ARF/cortical necrosis), 584.7 (ARF/medullary necrosis), 584.8 (ARF/necrosis), and 584.9 (ARF/ not otherwise specified). Second, 664 records were excluded because these patients received care in the intensive care unit or underwent mechanical ventilation (ICD-9-CM procedure codes $96.70,96.71,96.72)$ as these characteristics are generally thought to be associated with complicated ARF [10]. Third, 9 records were excluded because they involved children (age $<18$ years). Lastly, 188 records were excluded because the patients died during hospitalization and 94 records were excluded because these patients were admitted from an extended care facility. After the elimination of 2,102 patient records for the aforementioned reasons, 2,128 records of patients hospitalized with uncomplicated ARF were utilized for the final analysis.

The study populations for the comparable medical conditions requiring hospitalization in this dataset (table 1) were determined using similar exclusion criteria and defined by the following DRGs: 14 (cerebrovascular disorders except transient ischemic attack), 89 and 90 (pneumonia and pleurisy), 96 and 97 (bronchitis and asthma), 121 and 122 (circulatory disorders with acute myocardial infarct), 127 (heart failure), 174 and 175 (gastrointestinal bleeding), and 277 and 278 (cellulitis). 


\section{Independent Variables}

Four main categories of independent variables were evaluated in this analysis: demographic variables, hospitalization variables, payment variables, and disease variables. The definitions, descriptions, and classification of these independent variables have been discussed at length in our prior publication and therefore we will highlight only the most complicated elements here [11]. Demographic variables included: race, gender, age, and socioeconomic status. Socioeconomic status (income) was determined by the median annual household income for a patient's home zip code and defined as low if such annual income was less than 35,000 USD (200\% of poverty status, adjusted to USD in the year 2000) [16, 17]. Hospitalization variables included hospital type and source of admission. Hospital type was determined as primary academic, secondary academic, and non-academic according to a hospital's (i) membership in the Council of Teaching Hospitals, (ii) affiliation with a medical school, (iii) proximity of location to a medical school, and (iv) ratio of residents and fellows to hospital beds [11, 18]. Admission source encompassed physician/clinic referral, emergency room, and other/unknown. The sole payment variable was payer type (e.g., Medicare, Medicaid, private, and uninsured). Lastly, disease variables included both dialysis and severity of illness. Dialysis was defined by the presence of either of the following ICD-9-DM procedure codes 39.95 or 54.98 , while the severity of illness (e.g., low, moderate, high) was defined using the refined DRG (RDRG) method, which employs an algorithm based on secondary diagnostic codes and procedures $[19,20]$

\section{Dependent Variables}

Post-hospital care for a patient with uncomplicated ARF was defined by the occurrence of either extended facility care or home health care following his/her discharge from acute hospitalization. Extended facility care was defined as discharge to any of the following facilities: intermediate care facility, skilled nursing facility, rehabilitation hospital, or chronic hospital. Home health care was defined as discharge to home with receipt of services from a home health agency following hospital discharge. All of these care variables will be evaluated categorically in this analysis.

\section{Statistical Analysis}

Univariate analysis was performed to assess the significance of independent variables relative to the dependent variables (outcome measures). $\chi^{2}$ and Fisher's exact tests were employed for all categorical variables. Multi-collinearity between variables was determined both by using Spearman rank testing and assessment of tolerance index and variation inflation factors.

Multivariate analysis consisted of backward logistic regression. Appropriate effect modification terms as assessed by stratified analysis were evaluated for their statistical significance in the models. Confounding was investigated by studying a given factor's effect on the $\beta$-parameter estimate of the other existing covariates in the model. Caution was exercised to avoid over-fitting the model as at least 10 events in each outcome measure were needed per independent variable included. Model discrimination was assessed using the $c$ statistic while the fit of the models was evaluated by the Hosmer-Lemeshow statistic. All the statistical tests were 2 -tailed and $\mathrm{p}<0.05$ was considered statistically significant. All analyses were performed using SAS, version 9.1 (SAS Institute, Cary, N.C.).

Acute Renal Failure and Post-Hospital Care

\section{Results}

\section{Post-Hospital Care - Uncomplicated ARF and Other Medical Conditions}

As seen in table 1 , approximately $50 \%$ of surviving patients with uncomplicated ARF required post-hospital care following discharge with a slight preponderance of these individuals having extended facility care (27\%) compared with only having home health care (22\%). Individuals hospitalized primarily for cerebrovascular disorders incurred the greatest post-hospital care (65\%) while those with heart failure (52\%), myocardial infarction (44\%), uncomplicated ARF (49\%), and pneumonia (46\%) had similar high post-hospital care requirements. Cellulitis (37\%), gastrointestinal hemorrhage (36\%), and bronchitis (14\%) had lower levels of associated post-hospital care. Although the prevalence of uncomplicated ARF is $0.4 \%$, it ranks among the top $25 \%$ of most common medical conditions requiring hospitalization in this dataset.

\section{Population Characteristics: Post-Hospital Care versus Home and Extended Facility Care versus Home Health Care}

Overall, this uncomplicated ARF cohort consisted of roughly equal portions of men and women from predominately Caucasian backgrounds $(76 \%)$. A majority $(\approx 70 \%)$ of these patients were over 65 years of age and were insured by Medicare while a few subjects $(\approx 20 \%)$ had low incomes. A preponderance of patients were admitted from emergency rooms at academic hospitals $(\approx 65 \%)$. A minority of patients required dialysis (4\%) or had high severity of illness scores (20\%).

Several significant differences existed among the characteristics of uncomplicated ARF patients depending upon their discharge disposition (table 2). Compared with those individuals discharged to home, subjects requiring post-hospital care tended to be more often white ( 82 vs. $72 \%$ ), female ( 53 vs. $43 \%$ ), over the age of 65 years (84 vs. $53 \%$ ), Medicare recipients (83 vs. $59 \%$ ), hospitalized at non-academic centers (34 vs. $25 \%$ ), and severely ill ( 28 vs. $15 \%)$.

Differences also existed within the population of posthospital care requiring uncomplicated ARF patients by the specific type of post-hospital care that they received (table 2). Compared with those individuals only receiving home health care, subjects discharged to extended care facilities were more often female (58 vs. $47 \%$ ), over the age of 65 years ( 91 vs. $76 \%$ ), hospitalized at non-academic centers (41 vs. $27 \%$ ), and Medicare recipients (90 vs. $75 \%)$.

Am J Nephrol 2008;28:523-530 
Table 2. Patient characteristics (\%) by discharge disposition and type of post-hospital care

\begin{tabular}{|c|c|c|c|c|}
\hline Characteristic & $\begin{array}{l}\text { Home } \\
(51 \% ; n=1,092)\end{array}$ & $\begin{array}{l}\text { Post-hospital care } \\
(49 \% ; n=1,036)\end{array}$ & $\begin{array}{l}\text { Extended facility care } \\
(27 \% ; \mathrm{n}=577)\end{array}$ & $\begin{array}{l}\text { Home health care } \\
(22 \% ; \mathrm{n}=459)\end{array}$ \\
\hline \multicolumn{5}{|l|}{ Race } \\
\hline White & $72(\mathrm{n}=787)^{\mathrm{a}}$ & $82(\mathrm{n}=844)^{\mathrm{a}}$ & $84(\mathrm{n}=482)$ & $79(\mathrm{n}=362)$ \\
\hline Black & $13(\mathrm{n}=140)^{\mathrm{a}}$ & $9(\mathrm{n}=93)^{\mathrm{a}}$ & $7(\mathrm{n}=41)$ & $11(\mathrm{n}=52)$ \\
\hline Other & $15(\mathrm{n}=165)^{\mathrm{a}}$ & $9(\mathrm{n}=98)^{\mathrm{a}}$ & $9(\mathrm{n}=53)$ & $10(\mathrm{n}=45)$ \\
\hline \multicolumn{5}{|l|}{ Gender } \\
\hline Male & $57(\mathrm{n}=624)^{\mathrm{a}}$ & $47(\mathrm{n}=484)^{\mathrm{a}}$ & $42(\mathrm{n}=241)^{\mathrm{b}}$ & $53(\mathrm{n}=243)^{\mathrm{b}}$ \\
\hline Female & $43(\mathrm{n}=468)^{\mathrm{a}}$ & $53(\mathrm{n}=552)^{\mathrm{a}}$ & $58(\mathrm{n}=336)^{\mathrm{b}}$ & $47(\mathrm{n}=216)^{\mathrm{b}}$ \\
\hline \multicolumn{5}{|l|}{ Age, years } \\
\hline$<65$ & $47(\mathrm{n}=518)^{\mathrm{a}}$ & $16(\mathrm{n}=165)^{\mathrm{a}}$ & $9(\mathrm{n}=54)^{\mathrm{b}}$ & $24(\mathrm{n}=111)^{\mathrm{b}}$ \\
\hline$\geq 65$ to $\leq 75$ & $25(\mathrm{n}=277)^{\mathrm{a}}$ & $24(\mathrm{n}=244)^{\mathrm{a}}$ & $18(\mathrm{n}=104)^{\mathrm{b}}$ & $30(\mathrm{n}=140)^{\mathrm{b}}$ \\
\hline$>75$ to $\leq 85$ & $21(\mathrm{n}=230)^{\mathrm{a}}$ & $38(\mathrm{n}=393)^{\mathrm{a}}$ & $44(\mathrm{n}=251)^{\mathrm{b}}$ & $31(\mathrm{n}=142)^{\mathrm{b}}$ \\
\hline$>85$ & $6(\mathrm{n}=67)^{\mathrm{a}}$ & $23(\mathrm{n}=234)^{\mathrm{a}}$ & $29(\mathrm{n}=168)^{\mathrm{b}}$ & $14(\mathrm{n}=66)^{\mathrm{b}}$ \\
\hline \multicolumn{5}{|l|}{ Income } \\
\hline Low & $22(\mathrm{n}=241)^{\mathrm{a}}$ & $18(\mathrm{n}=183)^{\mathrm{a}}$ & $16(n=91)$ & $20(\mathrm{n}=92)$ \\
\hline Average & $78(\mathrm{n}=851)^{\mathrm{a}}$ & $82(\mathrm{n}=853)^{\mathrm{a}}$ & $84(\mathrm{n}=486)$ & $80(\mathrm{n}=367)$ \\
\hline \multicolumn{5}{|l|}{ Hospital type } \\
\hline Primary academic & $52(\mathrm{n}=569)^{\mathrm{a}}$ & $50(\mathrm{n}=514)^{\mathrm{a}}$ & $41(\mathrm{n}=238)^{\mathrm{b}}$ & $60(\mathrm{n}=276)^{\mathrm{b}}$ \\
\hline Secondary academic & $23(\mathrm{n}=251)^{\mathrm{a}}$ & $16(\mathrm{n}=164)^{\mathrm{a}}$ & $18(\mathrm{n}=103)^{\mathrm{b}}$ & $13(\mathrm{n}=61)^{\mathrm{b}}$ \\
\hline Non-academic & $25(\mathrm{n}=272)^{\mathrm{a}}$ & $34(\mathrm{n}=358)$ & $41(\mathrm{n}=236)^{\mathrm{b}}$ & $27(\mathrm{n}=122)^{\mathrm{b}}$ \\
\hline \multicolumn{5}{|l|}{ Admittance source } \\
\hline Referral & $35(\mathrm{n}=379)^{\mathrm{a}}$ & $21(\mathrm{n}=219)^{\mathrm{a}}$ & $17(\mathrm{n}=100)^{\mathrm{b}}$ & $26(\mathrm{n}=119)^{\mathrm{b}}$ \\
\hline Emergency room & $56(\mathrm{n}=614)^{\mathrm{a}}$ & $65(\mathrm{n}=673)^{\mathrm{a}}$ & $68(\mathrm{n}=393)^{\mathrm{b}}$ & $61(\mathrm{n}=280)^{\mathrm{b}}$ \\
\hline Other & $9(\mathrm{n}=99)^{\mathrm{a}}$ & $14(\mathrm{n}=144)^{\mathrm{a}}$ & $15(\mathrm{n}=84)^{\mathrm{b}}$ & $13(\mathrm{n}=60)^{\mathrm{b}}$ \\
\hline \multicolumn{5}{|l|}{ Insurance } \\
\hline Medicare & $59(\mathrm{n}=640)^{\mathrm{a}}$ & $83(\mathrm{n}=63)^{\mathrm{a}}$ & $90(\mathrm{n}=520)^{\mathrm{b}}$ & $75(\mathrm{n}=343)^{\mathrm{b}}$ \\
\hline Medicaid & $9(\mathrm{n}=101)^{\mathrm{a}}$ & $4(\mathrm{n}=43)^{\mathrm{a}}$ & $3(\mathrm{n}=15)^{\mathrm{b}}$ & $6(\mathrm{n}=28)^{\mathrm{b}}$ \\
\hline Private & $28(\mathrm{n}=303)^{\mathrm{a}}$ & $12(\mathrm{n}=120)^{\mathrm{a}}$ & $7(\mathrm{n}=40)^{\mathrm{b}}$ & $17(\mathrm{n}=80)^{\mathrm{b}}$ \\
\hline Uninsured & $4(\mathrm{n}=38)^{\mathrm{a}}$ & $1(\mathrm{n}=8)^{\mathrm{a}}$ & $1(\mathrm{n}=1)^{\mathrm{b}}$ & $2(\mathrm{n}=7)^{\mathrm{b}}$ \\
\hline \multicolumn{5}{|l|}{ Dialysis } \\
\hline Yes & $5(\mathrm{n}=51)^{\mathrm{a}}$ & $3(\mathrm{n}=31)^{\mathrm{a}}$ & $3(\mathrm{n}=16)$ & $3(\mathrm{n}=15)$ \\
\hline No & $95(\mathrm{n}=1,041)^{\mathrm{a}}$ & $97(\mathrm{n}=1,005)^{\mathrm{a}}$ & $97(\mathrm{n}=561)$ & $97(\mathrm{n}=444)$ \\
\hline \multicolumn{5}{|l|}{ Severity of illness } \\
\hline Low & $6(\mathrm{n}=68)^{\mathrm{a}}$ & $2(\mathrm{n}=22)^{\mathrm{a}}$ & $1(\mathrm{n}=6)^{\mathrm{b}}$ & $3(\mathrm{n}=16)^{\mathrm{b}}$ \\
\hline Moderate & $79(\mathrm{n}=862)^{\mathrm{a}}$ & $70(\mathrm{n}=723)^{\mathrm{a}}$ & $69(\mathrm{n}=399)^{\mathrm{b}}$ & $70(\mathrm{n}=324)^{\mathrm{b}}$ \\
\hline High & $15(\mathrm{n}=162)^{\mathrm{a}}$ & $28(\mathrm{n}=291)^{\mathrm{a}}$ & $30(\mathrm{n}=172)^{\mathrm{b}}$ & $26(\mathrm{n}=119)^{\mathrm{b}}$ \\
\hline
\end{tabular}

$\mathrm{n}=$ Patient record count. ${ }^{\mathrm{a}} \mathrm{p}<0.05$, home versus post-hospital care. ${ }^{\mathrm{b}} \mathrm{p}<0.05$, extended facility care versus home health care.

\section{Multivariable Analysis for Factors Associated with Post-Hospital Care}

As seen in table 3 , several factors were associated with the receipt of post-hospital care among surviving patients with uncomplicated ARF. A significant and graduated trend was seen between post-hospital care and advancing age as well as post-hospital care and higher levels of illness severity $(\mathrm{p}<0.0001)$. Female gender $(\mathrm{OR}=1.36$; $95 \%$ CI 1.12-1.65) and admission from an emergency room $(\mathrm{OR}=1.70$; 95\% CI 1.36-2.13) were both independently associated with the receipt of post-hospital care. A clear consistent trend existed between less post-hospital care, regardless of specific type, and acute hospitalization at secondary academic hospitals (OR $=0.47$; $95 \%$ CI $0.35-$ $0.63)$. The relationship between hospitalization at primary academic medical centers and post-hospital care depended on the specific type of post-hospital care - lesser receipt of extended facility care $(\mathrm{OR}=0.52$; $95 \%$ CI $0.41-$ $0.67)$ but greater receipt of home health care $(\mathrm{OR}=1.67$; 95\% CI 1.29-2.15). 
Table 3. Factors associated with post-hospital care for patients with uncomplicated ARF

\begin{tabular}{|c|c|c|c|c|c|c|}
\hline \multirow[t]{2}{*}{ Characteristic } & \multicolumn{2}{|c|}{ Post-hospital care } & \multicolumn{2}{|c|}{ Extended facility care } & \multicolumn{2}{|c|}{ Home health care } \\
\hline & adjusted OR & $95 \% \mathrm{CI}$ & adjusted OR & $95 \% \mathrm{CI}$ & adjusted OR & $95 \% \mathrm{CI}$ \\
\hline \multicolumn{7}{|l|}{ Race } \\
\hline White & $1.00^{\mathrm{a}}$ & & NS & & $1.00^{\mathrm{a}}$ & \\
\hline Black & 0.91 & $0.66-1.26$ & NS & & 0.98 & $0.69-1.38$ \\
\hline Other & 0.64 & $0.47-0.87$ & NS & & 0.70 & $0.49-0.99$ \\
\hline \multicolumn{7}{|l|}{ Gender } \\
\hline Male & $1.00^{\mathrm{a}}$ & & $1.00^{\mathrm{a}}$ & & NS & \\
\hline Female & 1.36 & $1.12-1.65$ & 1.61 & $1.29-2.00$ & NS & \\
\hline \multicolumn{7}{|l|}{ Age } \\
\hline$<65$ & $1.00^{\mathrm{a}}$ & & $1.00^{\mathrm{a}}$ & & $1.00^{\mathrm{a}}$ & \\
\hline$\geq 65$ to $\leq 75$ & 2.81 & $2.17-3.64$ & 2.71 & $1.89-3.89$ & 2.02 & $1.51-2.70$ \\
\hline$>75$ to $\leq 85$ & 5.26 & $4.07-6.79$ & 6.67 & $4.79-9.29$ & 1.65 & $1.24-2.20$ \\
\hline$>85$ & 10.54 & $7.49-14.84$ & 11.76 & $8.11-17.06$ & 1.63 & $1.15-2.32$ \\
\hline \multicolumn{7}{|l|}{ Income } \\
\hline Low & NS & & 0.72 & $0.54-0.96$ & NS & \\
\hline Average & NS & & $1.00^{\mathrm{a}}$ & & NS & \\
\hline \multicolumn{7}{|l|}{ Hospital type } \\
\hline Primary academic & 0.97 & $0.77-1.22$ & 0.52 & $0.41-0.67$ & 1.67 & $1.29-2.15$ \\
\hline Secondary academic & 0.47 & $0.35-0.63$ & 0.47 & $0.35-0.65$ & 0.75 & $0.53-1.05$ \\
\hline Non-academic & $1.00^{\mathrm{a}}$ & & $1.00^{\mathrm{a}}$ & & $1.00^{\mathrm{a}}$ & \\
\hline \multicolumn{7}{|l|}{ Admit Source } \\
\hline Referral & $1.00^{\mathrm{a}}$ & & $1.00^{\mathrm{a}}$ & & NS & \\
\hline Emergency room & 1.70 & $1.36-2.13$ & 2.03 & $1.54-2.68$ & NS & \\
\hline Other & 2.30 & $1.64-3.24$ & 2.56 & $1.74-3.75$ & NS & \\
\hline \multicolumn{7}{|l|}{ Severity } \\
\hline Low & 0.46 & $0.27-0.78$ & 0.25 & $0.11-0.60$ & 0.92 & $0.52-1.62$ \\
\hline Moderate & $1.00^{\mathrm{a}}$ & & $1.00^{\mathrm{a}}$ & & $1.00^{\mathrm{a}}$ & \\
\hline High & 2.06 & $1.62-2.61$ & 1.75 & $1.36-2.24$ & 1.39 & $1.09-1.78$ \\
\hline
\end{tabular}

a Reference value.

\section{Discussion}

This study underscores the significant post-hospital care requirements that individuals with uncomplicated ARF encumber. Nearly $50 \%$ of the uncomplicated ARF patients required either extended facility care or home health care. Prior investigations from the 1990s noted that up to $44 \%$ of critically ill individuals who survive ARF need some type of post-hospital extended care [2123]. Two recent studies involving nationwide samples of ARF patients with varying disease severity and complexity found that roughly $25 \%$ these patients were discharged to long-term care facilities, which was twice the rate of discharge to these facilities found among patients without ARF $[13,14]$.

Consistent with these studies, we found that $27 \%$ of ARF patients received extended facility care, even in the less severe form of ARF represented by this analysis [13, 14]. Moreover, another $22 \%$ of survivors with uncomplicated ARF received home health services, which further emphasizes the spectrum of resources that appear to be needed to facilitate complete recovery from this condition.

It is even more revealing to consider these post-hospital care services relative to those associated with other prominent medical illnesses. The unadjusted aggregate post-hospital care requirements for uncomplicated ARF are similar to those of well-recognized disabling conditions such as congestive heart failure and myocardial infarction. In a broader context, this finding parallels the relatively high costs and lengths of stay for uncomplicated ARF compared to other serious conditions as shown in our prior work, further underscoring the significant resource utilization associated this condition [11]. Fur- 
thermore, it is important to consider the mounting economic burden incurred by post-hospital care. In 2000, nearly 125 billion USD or $10 \%$ of American national health expenditures were allocated for nursing home and home health care services, which often occur following acute hospitalization [24]. Costs for these services are projected to almost double to nearly 240 billion USD by 2011 [24].

This study is distinct and complementary to prior investigations in several key ways. First, this analysis represents patients with uncomplicated ARF, where ARF was chiefly responsible for hospitalization while other medical problems played far less important roles. This strategy allowed us to more specifically link ARF to posthospital care requirements. The frequency of post-hospital care requirements for the excluded complicated ARF patients in this dataset were found to be nearly $60 \%$ (data not shown), but it is unclear if these additional post-discharge resources are obligated by ARF or the other nonrenal organ failures. Second, in order to further clarify the association between ARF and extended facility care, we excluded hospitalized ARF patients who had been admitted from such facilities. This important methodological detail has not been delineated in prior work. Third, we captured individuals with ARF who were discharged home but received home health services. Although we were not able to determine if patients were receiving home health care prior to admission and hence its association with uncomplicated ARF may be overstated, this component of post-hospital care has not been evaluated previously for ARF. Approximately $25 \%$ of recent national health expenditures for post-hospital care were specifically used for home health care and it is projected that this percentage will rise to $30 \%$ over the next decade [24].

Factors independently associated with the receipt of post-hospital care in ARF patients have not been characterized until this study. Patient-related characteristics appeared to have a particular influence on the occurrence of post-hospital care services, including age, gender, and severity of illness. Older age and female gender were independently associated with the receipt of post-hospital care, extending findings from prior reports [13]. Several investigators have found a greater frequency of functional loss from delirium and deconditioning with advancing age during acute hospitalization and a subsequent higher requirement of nursing home placement in the elderly $[22,23,25,26]$. A variety of factors may underlie these observations including diminished physical reserve against an acute disease process and disproportionate complications from its therapies [27, 28]. Especially when considering ARF, issues such as polypharmacy, frequent blood draws, volume overload, and complications from physical restraints such as urinary catheter placement likely play significant roles. Alternatively, the elderly may receive less aggressive and intense hospital care even after accounting for patient preferences, which could precipitate greater functional loss during hospitalization [11, 2931]. Female gender has been noted in prior studies to be associated with a greater frequency of discharge to nursing homes following acute hospitalization $[22,25]$. The reason for this finding is not clear but likely relates to the presence of spousal support and other social support at home, which was not captured by our analysis. Similar to findings in our prior work regarding uncomplicated ARF and hospital resource utilization, the RDRG severity of illness classes (low, moderate, high) maintain a strong graduated association with the receipt of post-hospital care in uncomplicated ARF patients [11]. This investigation is the first to demonstrate the utility of this risk-adjustment model in forecasting post-hospital resource use for an acute illness $[19,20]$.

While less prominent than patient-related factors, hospital factors also appeared to have an important relationship with the receipt of post-hospital care. A significant trend and association existed between less post-hospital care services and hospitalization at academic medical centers, particularly with regard to extended facility care and secondary academic hospitals. Prior work involving this same cohort of patients with uncomplicated ARF demonstrated that patients hospitalized at academic hospitals also had shorter hospital lengths of stay compared with those hospitalized at non-academic hospitals [11]. Hence, it does not appear that a differential shift in care between the acute hospital and post-hospital setting among academic and non-academic hospitals explains this finding. Previous analyses have reached differing conclusions regarding the association between post-hospital care services following acute medical illness and the teaching status of a hospital [26,32]. Unfortunately, while our findings add further attention to this issue, they are limited by the small number of studied hospitals and few details regarding provision of care available for this analysis. In order to more fully understand these relationships, a larger and more thorough examination of influential factors such as health organizational structure and for-profit status is needed.

A few limitations in this present study are important to note. First, although prior investigators and Massachusetts hospitals have used data from the Massachusetts 
DHCFP repeatedly to successfully complete other analytic endeavors, limitations in the quality and completeness of the information from this dataset may exist [11, 18]. We did not have access to all clinically important ARF attributes such as serum creatinine values and urine output, associated comorbid illnesses such as chronic kidney disease and congestive heart failure, and patient risk factors for delirium and deconditioning such as baseline cognitive function and ambulatory status that could influence the receipt of post-hospital care. However, by limiting the study cohort to patients chiefly with only kidney dysfunction, employing a robust severity of illness measure, and assessing the role of numerous concomitant important characteristics, we believe that the relationship between post-hospital care and uncomplicated ARF has been appropriately characterized. Second, our analysis focused on patient receipt of post-hospital care services and not on patient need of these services. It is possible that these two outcome measures may not always be equivalent due to patient and provider choice as well as particular health institution policies. Third, although DRG and ICD-9-CM codes for ARF have been used in many recent studies, this methodology is potentially limited by error and disease misclassification [13, 33-37]. A recent analysis evaluating the diagnostic utility of ICD-9-CM codes to identify individuals hospitalized with non-dialysis requiring ARF found high specificity, negative predictive value, and positive predictive value but low sensitivity for this methodology [38]. Along with similar findings elsewhere, it suggests that analyses utilizing ICD-9-CM codes to define ARF cohorts will not be significantly compromised by the inclusion of non-ARF individuals, but they may not include all individuals with clinically important ARF $[13,14,37]$. In addition to errors in chart review, coding, and lack of standard disease definitions, one of the major explanations for this higher false-negative rate (i.e., lower sensitivity) for ARF identification is the underreporting of secondary conditions $[13,14,36-39]$. Since we defined ARF not by secondary diagnoses but only by the presence of a primary ICD-9$\mathrm{CM}$ diagnosis, our methodology would be expected to yield a much higher sensitivity for ARF identification. Lastly, the current study was limited to hospitals in Massachusetts and therefore its results may be less generalizable to ARF patients in other areas of the United States.

Uncomplicated ARF appears to encumber afflicted individuals with frequent stays at extended care facilities and the use of home health services. Since it is becoming clear that uncomplicated ARF necessitates significant health care resources throughout the continuum of care, it is important that researchers take post-hospital care needs into account in future studies dealing with the economics of ARF. Furthermore, as the incidence of ARF and national health expenditures continue to rise, it is increasingly important to develop and test strategies that optimize resource use for this condition.

\section{Acknowledgments}

M.J.F. was supported by an institutional National Research Service Award grant during the study period. M.J.F. is currently supported by a Department of Veterans Affairs Health Services Research and Development Career Development Award. C.R.P. is supported by grant No. K23-DK064689-01 from the National Institutes of Diabetes and Digestive and Kidney Diseases, the National Institutes of Health.

\section{References}

1 Kaufman J, Dhakal M, Patel B, Hamburger R: Community-acquired acute renal failure. Am J Kidney Dis 1991;17:191-198.

-2 Shusterman N, Strom BL, Murray TG, Morrison G, West SL, Maislin G: Risk factors and outcome of hospital-acquired acute renal failure. Am J Med 1987;83:65-71.

-3 Hou SH, Bushinsky DA, Wish JB, Cohen JJ, Harrington JT: Hospital-acquired renal insufficiency: a prospective study. Am J Med 1983;74:243-248.

4 Liano F, Pascual J: Epidemiology of acute renal failure: a prospective, multicenter, community-based study. Madrid Acute Renal Failure Study Group. Kidney Int 1996;50: 811-818.

Acute Renal Failure and Post-Hospita Care
5 Nash K, Hafeez A, Hou S: Hospital-acquired renal insufficiency. Am J Kidney Dis 2002; 39:930-936.

6 de Mendonca A, Vincent JL, Suter PM, et al: Acute renal failure in the ICU: risk factors and outcome evaluated by the SOFA score. Intensive Care Med 2000;26:915-921.

7 Hoste EA, Lameire NH, Vanholder RC, Benoit DD, Decruyenaere JM, Colardyn FA: Acute renal failure in patients with sepsis in a surgical ICU: predictive factors, incidence, comorbidity, and outcome. J Am Soc Nephrol 2003; 14:1022-1030.

8 Menashe PI, Ross SA, Gottlieb JE: Acquired renal insufficiency in critically ill patients. Crit Care Med 1988;16:1106-1109.
-9 Brivet FG, Kleinknecht DJ, Loirat P, Landais PJ: Acute renal failure in intensive care units - causes, outcome, and prognostic factors of hospital mortality; a prospective, multicenter study. French Study Group on Acute Renal Failure. Crit Care Med 1996;24:192198.

10 Mehta RL, Chertow GM: Acute renal failure definitions and classification: time for a change? J Am Soc Nephrol 2003;14:21782187.

-11 Fischer MJ, Brimhall BB, Lezotte DC, Glazner JE, Parikh CR: Uncomplicated acute renal failure and hospital resource utilization: a retrospective mulitcenter analysis. Am J Kidney Dis 2005;46:1049-1057. 
12 Chertow GM, Burdick E, Honour M, Bonventre JV, Bates DW: Acute kidney injury, mortality, length of stay, and costs in hospitalized patients. J Am Soc Nephrol 2005;16: 3365-3370.

-13 Liangos O, Wald R, O’Bell JW, Price L, Pereira B, Jaber BL: Epidemiology and outcomes of acute renal failure in hospitalized patients: a national survey. Clin J Am Soc Nephrol 2006;1:43-51.

- 14 Waikar SS, Curhan GC, Wald R, McCarthy EP, Chertow GM: Declining mortality in pa tients with acute renal failure, 1988-2002. J Am Soc Nephrol 2006;17:1143-1150.

15 International Classification of Diseases, 9th Revision, Clinical Modification. Salt Lake City, Medicode, 2004.

16 Website: US Census Bureau, url: http://www. census.gov/hhes/poverty/threshld/ thresh99.html, accessed 5/1/04.

17 Website: US Census Bureau, url: http://www. census.gov/hhes/poverty/threshld/ thresh00.html, accessed 5/1/04.

18 Brimhall BB, Dean T, Hunt EL, Siegrist RB, Reiquam W: Age and laboratory costs for hospitalized medical patients. Arch Pathol Lab Med 2003;127:169-177.

19 Freeman JL, Fetter RB, Park H, et al: Diagnosis-related group refinement with diagnosis- and procedure-specific comorbidities and complications. Med Care 1995;33:806827.

20 Iezzoni LI: The risks of risk adjustment. JAMA 1997;278:1600-1607.

$>21$ Chertow GM, Christiansen CL, Cleary PD, Munro C, Lazarus JM: Prognostic stratification in critically ill patients with acute renal failure requiring dialysis. Arch Intern Med 1995; 155:1505-1511.
22 Mangano CM, Diamondstone LS, Ramsay JG, Aggarwal A, Herskowitz A, Mangano DT: Renal dysfunction after myocardial revascularization: risk factors, adverse outcomes, and hospital resource utilization. The Multicenter Study of Perioperative Ischemic Research Group. Ann Intern Med 1998; 128:194-203.

23 Morris JA Jr, Mucha P Jr, Ross SE, et al: Acute posttraumatic renal failure: a multicenter perspective. J Trauma 1991;31:1584-1590.

24 Heffler S, Smith S, Won G, Clemens MK, Keehan S, Zezza M: Health spending projections for 2001-2011: the latest outlook Health Aff (Millwood) 2002;21:207-218.

25 Rudberg MA, Sager MA, Zhang J: Risk factors for nursing home use after hospitalization for medical illness. J Gerontol A Biol Sci Med Sci 1996;51:M189-M194.

26 Kane RL, Matthias R, Sampson S: The risk of placement in a nursing home after acute hospitalization. Med Care 1983;21:1055-1061.

$\checkmark 27$ Sager MA, Franke T, Inouye SK, et al: Functional outcomes of acute medical illness and hospitalization in older persons. Arch Intern Med 1996;156:645-652

28 Covinsky KE, Palmer RM, Fortinsky RH, et al: Loss of independence in activities of daily living in older adults hospitalized with medical illnesses: increased vulnerability with age. J Am Geriatr Soc 2003;51:451-458.

29 Perls TT, Wood ER: Acute care costs of the oldest old: they cost less, their care intensity is less, and they go to nonteaching hospitals. Arch Intern Med 1996;156:754-760.

30 Hamel MB, Lynn J, Teno JM, et al: Age-related differences in care preferences, treatment decisions, and clinical outcomes of seriously ill hospitalized adults: lessons from SUPPORT. J Am Geriatr Soc 2000;48(suppl): S176-S182.
31 Hamel MB, Davis RB, Teno JM, et al: Older age, aggressiveness of care, and survival for seriously ill hospitalized adults. Ann Intern Med 1999;131:721-728.

32 Bronskill SE, Normand SL, McNeil BJ: Postacute service use following acute myocardial infarction in the elderly. Health Care Financ Rev 2002;24:77-89.

33 Xue JL, Daniels F, Star RA, et al: Incidence and mortality of acute renal failure in Medicare beneficiaries, 1992 to 2001. J Am Soc Nephrol 2006;17:1135-1142.

34 Iezzoni LI, Moskowitz MA: Clinical overlap among medical diagnosis-related groups. JAMA 1986;255:927-929.

35 Hsia DC, Krushat WM, Fagan AB, Tebbutt JA, Kusserow RP: Accuracy of diagnostic coding for Medicare patients under the prospective-payment system. N Engl J Med 1988;318:352-355

>36 Lloyd SS, Rissing JP: Physician and coding errors in patient records. JAMA $1985 ; 254$ : 1330-1336.

37 Waiker SS, Wald R, Chertow GM, et al: Validity of International Classification of Diseases, Ninth Revision, Clinical Modification Codes for Acute Renal Failure. J Am Soc Nephrol 2006;17:1688-1694.

38 Jencks SF: Accuracy in recorded diagnoses: JAMA 1992;267:2238-2239.

>39 Iezzoni LI, Foley SM, Daley J, Hughes J, Fisher ES, Heeren T: Comorbidities, complications and coding bias. Does the number of diagnoses codes matter in predicting in-hospital mortality? JAMA 1992;267:2197-2203. 